\title{
SISTEM INFORMASI PEMBAYARAN BIMBEL RUMAH BELAJAR TARTILA
}

\author{
Nurlaela $^{1}$, Dewi Driyani ${ }^{2}$, Ek Ajeng Rahmi Pinahayu ${ }^{3}$ \\ ${ }^{1,2,3}$ Teknik Informatika, Fakultas Teknik dan Ilmu Komputer, Universitas Indraprasta PGRI \\ Jalan Raya Tengah No.80, Kelurahan Gedong, Pasar Rebo, Jakarta Timur \\ 1urlaela@gmail.com, 2dewi.driyani2@gmail.com, ${ }^{3}$ ekajeng rahmipinahayu@yahoo.com
}

\begin{abstract}
ABSTRAK
Penulis melakukan penelitian di Rumah Belajar Tartila Depok yang merupakan tempat bimbingan belajar. Pada proses administrasi dan transaksi pembayaran yang digunakan masih manual, penyimpanan data serta pembuatan laporan masih menggunakan media kertas yang menyebabkan keterlambatan data yang masuk serta menyebabkan penginputan data yang kurang efektif. Tujuan penelitian ini yaitu membuat Sistem Informasi Pembayaran Bimbel Rumah Belajar Tartila untuk memudahkan pekerjaan administrasi dalam mengelola data siswa, data kelas, data transaksi pembayaran dan pembuatan laporan . Metode penelitian digunakan adalah menggunakan Research and Development (R\&D). Adapun file pendukung dalam membuat program ini seperti java dan MySQl. Kesimpulan dari penelitian ini adalah aplikasi dapat memudahkan pengelolaan pendataan dan administrasi di Rumah Belajar Tartila.
\end{abstract}

Kata Kunci : Sistem Informasi, Pembayaran, Java, MySQL

\begin{abstract}
The author conducted research at Tartila Depok Learning House which is a place for tutoring. In the administrative processes and payment transactions used are still manual, data storage and report generation still use paper media which causes delays in incoming data and causes ineffective data input. The purpose of this study is to create a Tartila Learning House Tuition Payment Information System to facilitate administrative work in managing student data, class data, payment transaction data and report generation . The research method used is Research and Development (R\&D). The supporting files in making this program such as java and MySQL. The conclusion of this study is that the application can facilitate the management of data collection and administration at the Tartila Learning House.
\end{abstract}

Key Word : Information Systems, Payment, Java, MySQL

\section{PENDAHULUAN}

Rumah Belajar Tartila Depok merupakan salah satu badan usaha yang bergerak dalam bidang bimbingan belajar mulai dari Pra TK, TK, dan SD . Rumah Belajar Tartila Depok memiliki banyak peminat hampir setiap ajaran baru jumlah siswanya bertambah. Bimbingan Belajar dibutuhkan untuk semua individu, dan memiliki tujuan untuk dapat membantu individu dalam memahami diri dan bertindak wajar (Sriyono, 2016).

Dalam hal ini, bimbingan belajar mengalami kesulitan dalam melakukan kegiatan administrasi pembayaran biaya bimbingan dan juga kesulitan dalam pemberian bukti pembayaran serta pencarian data pembayaran. Sistem administrasi pada Rumah Belajar Tartila Depok masih dikerjakan dengan manual. Berdasarkan uraian masalah pada Rumah Belajar Tartila Depok maka saya sebagai peneliti membuat dan merancang sebuah sistem aplikasi pada Rumah Belajar Tartila Depok yang dapat mempermudah proses administrasi pembayaran dan pembuatan laporan keuangan. Dengan berbagai permasalahan yang terjadi saya akan membuat Sistem Informasi Pembayaran Pada Rumah Belajar Tartila.

"Sistem adalah jaringan membuat prosedur berdasarkan pola terpadu untuk melakukan kegiatan pokok perusahaan dan semua sistem memiliki input, proses, output, dan umpan balik (Ashari, 2014)“.

"Informasi adalah data yang diolah untuk penerima dan dapat dimanfaatkan untuk mengambil keputusan yang akan datang atau 
saat ini dan berarti bagi penerima (Syukron \& Hasan, 2017)" .

"Sistem Informasi adalah urutan prosedur formal dan pengelompokkan data untuk diproses menjadi informasi dan dapat digunakan (Efendi et al., 2019)".

"SPP (Sumbangan Penunjang Pendidikan) yaitu pembayaran atau iuran bulanan wajib untuk siswa di sekolah (Yusran, 2020)".

Dengan adanya sistem informasi pembayaran di tempat bimbel tersebut dapat mempermudah administrasi dan pembuatan laporan pembayaran. Dalam membuat aplikasi sistem informasi pembayaran bimbel saya menggunakan perangkat pendukung seperti :

"Java adalah bahasa pemrograman berorientasi objek serta bebas platform, java dikembangkan oleh SUN Micro System melakukan proses pengembangan dengan bahasa entreprise sebagai keunggulannya (Rusmayanti, 2015)”.

"MySQL adalah database server, yang memiliki fungsi untuk membuat database (Yusran, 2020)".

Tujuan penelitian yang ingin dicapai dalam Sistem Informasi Pembayaran Bimbel Rumah Belajar Tartila adalah untuk merancang aplikasi pembayaran agar membantu mengelola pendataan siswa, pendataan kelas dan pendataan pembayaran Rumah Belajar Tartila Depok. Untuk menyimpan data - data siswa, kelas, tagihan dan pembayaran agar mempermudah dalam pencarian dan penagihan. Untuk merancang aplikasi pembayaran agar membantu mengelola membuat laporan pembayaran di Rumah Belajar Tartila Depok menjadi lebih akurat.

Manfaat penelitian yang ingin dicapai dalam Sistem Informasi Pembayaran Bimbel Rumah Belajar Tartila adalah Proses administrasi pembayaran dan laporan secara terkomputerisasi sehingga dapat mempermudah pekerjaan.

\section{METODE PENELITIAN}

Berdasarkan tujuan dan rumusan masalah di atas, jenis penelitian yang saya digunakan dalam penelitian ini adalah menggunakan
Research and Development (R\&D).

Research and Development adalah langkahlangkah atau proses dalam menyempurnakan produk atau mengembangkan produk baru (Anjani et al., 2020).

Adapun teknik pengumpulan data pada penelitian ini adalah (Dewi \& Malfiany, 2017)

a. Wawancara dengan karyawan mengenai semua kegiatan yang terjadi. Dengan melakukan wawancara kepada pemilik Rumah Belajar Tartila mempermudah dalam mengetahui masalah yang terjadi disana.

b. Observasi dipakai untuk menghasilkan data yang dapat dilihat dan diamati secara langsung mengenai Sistem Informasi Pembayaran Bimbel.

Penelitian dilakukan selama 4 bulan yakni bulan April sampai dengan Juli 2021. Tempat penulis melakukan penelitian berada di Rumah Belajar Tartila Jl. Kali Licin No.25.

\section{HASIL DAN PEMBAHASAN}

Berdasarkan masalah yang terdapat pada Rumah Belajar Tartila, maka penulis memberikan beberapa alternatif penyelesaian masalah tersebut, yaitu :

1. Membuat perancangan sistem informasi untuk Rumah Belajar.

2. Menggunakan database MySQL sebagai media penyimpanan data.

3. Menggunakan plugin iReport pada netbeans untuk membuat laporan. iReport dapat digunakan untuk membuat laporan dan mengurangi kesalahan.

Peneliti menggunakan DFD (Data Flow Diagram) untuk merancang sistem. DFD adalah teknik grafis untuk menggambarkan transformasi dan aliran informasi (Herlambang \& Setyawati, 2015) . 


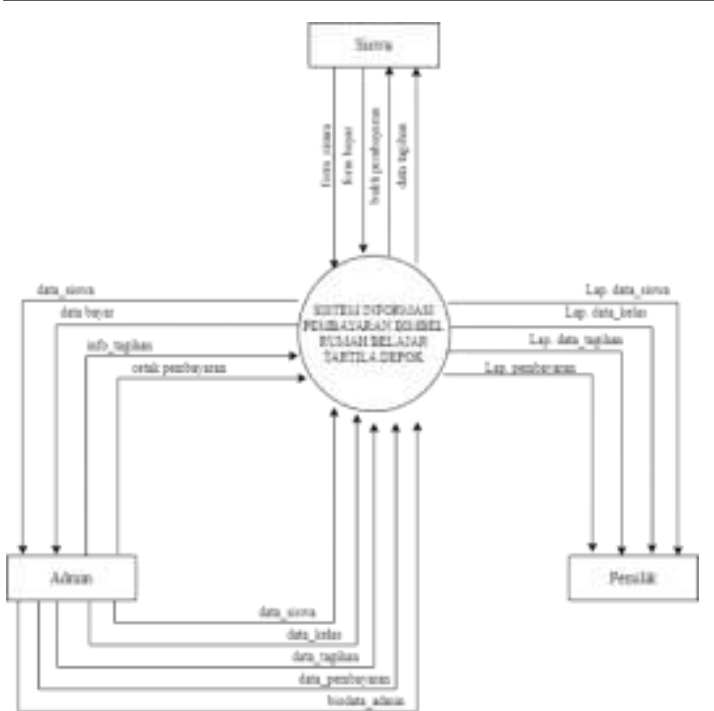

Gambar 1. Diagram Konteks yang Diusulkan

ERD (Entity Relationship Diagram) adalah model untuk menggambarkan data dalam bentuk entitas, atribut dan hubungan antar entitas. ERD hanya bersifat konseptual dan tidak tergantung pada produk DBMS (Usada et al., 2012) . ERD pada penelitian ini terdapat entity sebagai pengguna aplikasi yaitu admin, siswa dan pemilik .

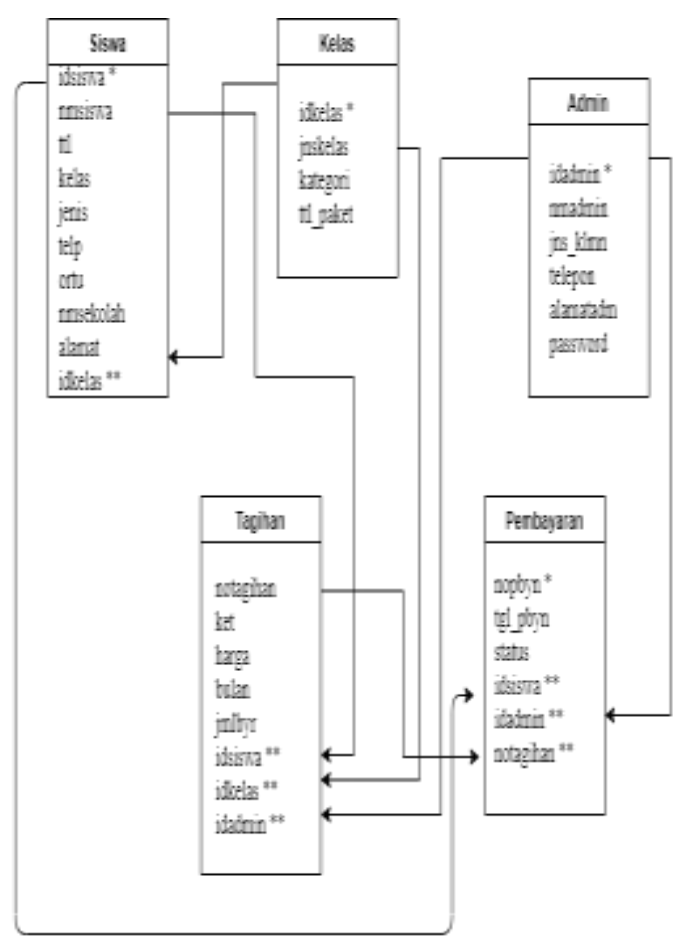

Gambar 2. Database Berelasi

Gambar diatas merupakan database yang saling berelasi yang telah peneliti buat, yang terdiri dari 5 tabel yaitu siswa, kelas, admin, tagihan dan pembayaran.

\section{Tampilan Sistem Informasi Pada rumah Belajar Tartila}

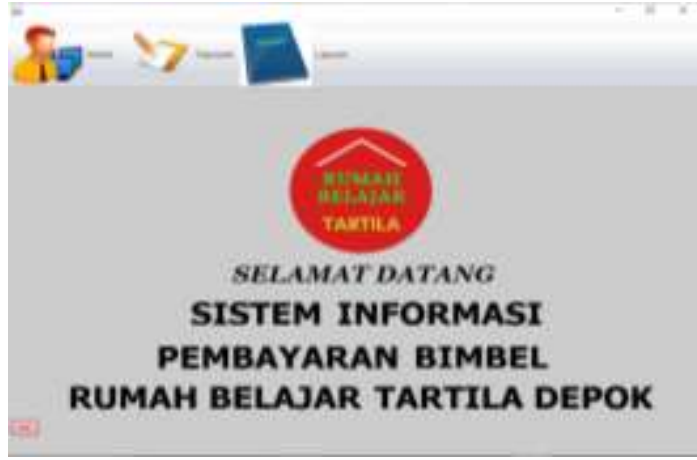

Gambar 3. Tampilan Menu Utama

Gambar di atas menampilkan tampilan Menu Utama pada Sistem Informasi Pembayaran Rumah Belajar Tartila.

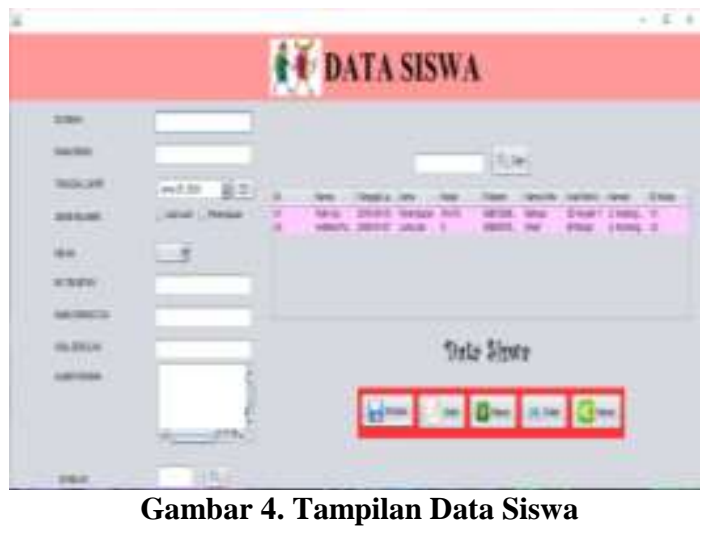

Tampilan di atas merupakan rancangan tampilan form data siswa yang berisi data siswa.

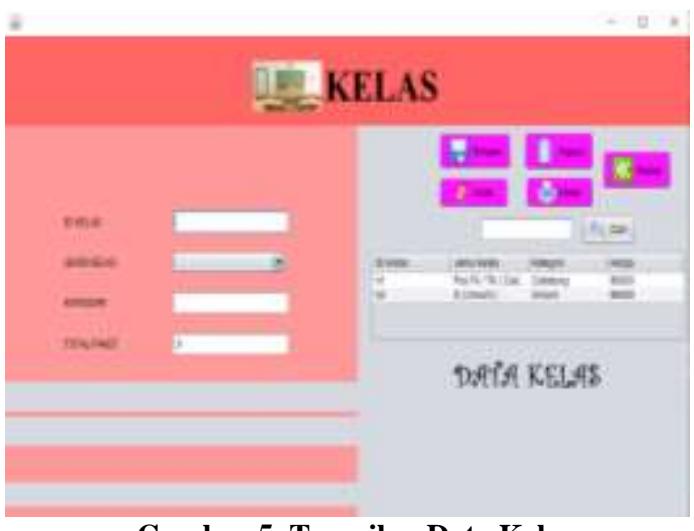

Gambar 5. Tampilan Data Kelas

Tampilan di atas merupakan rancangan tampilan form data kelas yang ada pada Rumah Belajar Tartila. 


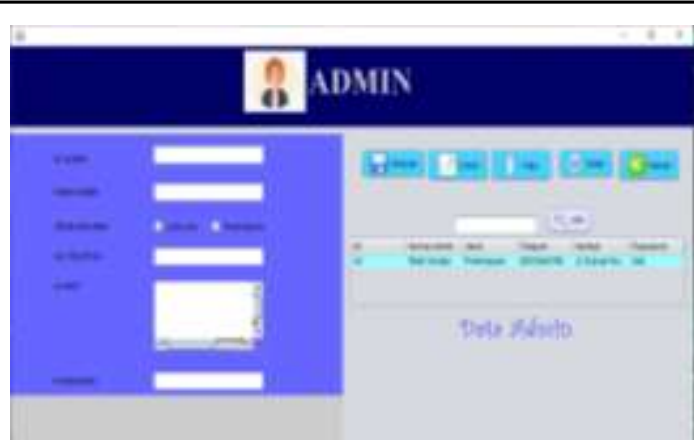

Gambar 6. Tampilan Data Admin

Tampilan di atas merupakan rancangan tampilan form data admin yang berisi biodata admin.

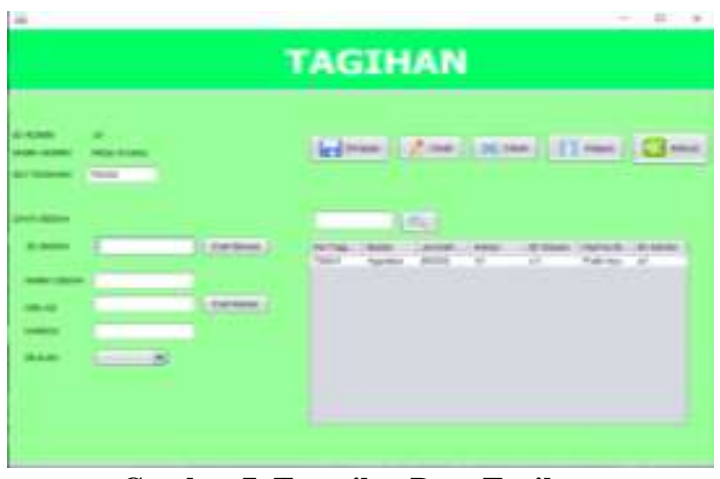

Gambar 7. Tampilan Data Tagihan

Tampilan di atas merupakan rancangan tampilan form data tagihan yang ada pada Rumah Belajar Tartila yang akan diinformasikan kepada siswa.

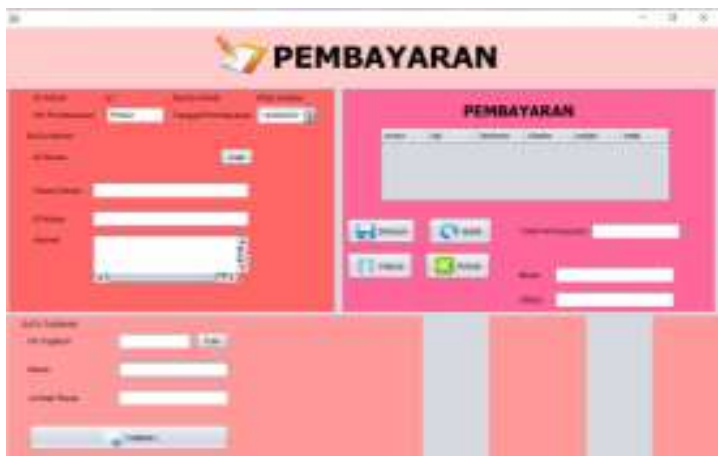

Gambar 8. Tampilan Transaksi Pembayaran

Tampilan di atas merupakan rancangan tampilan form pembayaran yang ada pada Rumah Belajar Tartila.

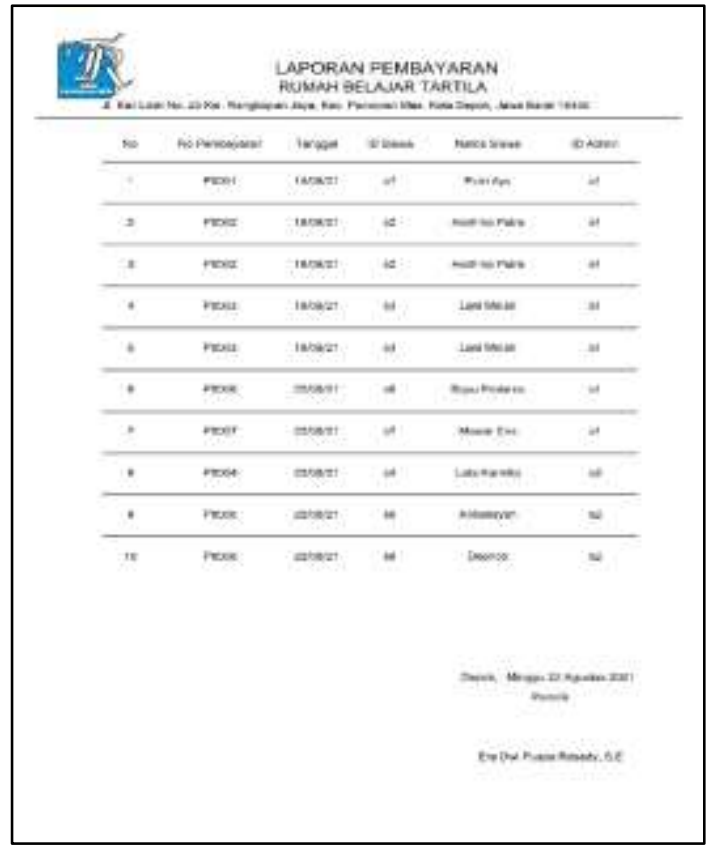

Gambar 9. Tampilan Laporan Pembayaran

Tampilan laporan data pembayaran ini berisi data-data yang ada pada tabel data pembayaran dan memberikan informasi data siswa yang sudah melakukan pembayaran.

\section{SIMPULAN DAN SARAN}

Setelah mengetahui keadaan sistem informasi pada Rumah Belajar Tartila yaitu pendataan dan pembayaran masih memakai sistem manual, maka dibuatlah sebuah rancangan yang dapat membantu mengelola pendataan, mempermudah menyimpan data siswa, data tagihan, data pembayaran dan memudahkan untuk pembuatan laporan pembayaran. Setelah aplikasi ini diterapkan pada Rumah Belajar Tartila proses pendataan dan pembayaran menjadi lebih efisien dan efektif.

Adapun saran sebagai peneliti adalah tampilan dalam pembuatan program ini ada baiknya untuk kedepannya dibuat tampilan yang lebih menarik lagi dan mengembangkannya sesuai kebutuhan. Diperlukan adanya pengecekan dan pengelolahan secara berkala .

\section{DAFTAR PUSTAKA}

Anjani, T., Niswati, Z., \& Mutia, I. (2020). Perancangan Aplikasi Peminjaman Buku Perpustakaan Pada SDN Mekarjaya 11 Depok. STRING (Satuan Tulisan Riset Dan Inovasi Teknologi), 
$5(1)$

101. https://doi.org/10.30998/string.v5i1.48 83

Ashari, A. (2014). Sistem Informasi Pembayaran Sumbangan Pembinaan Pendidikan (SPP) pada Sekolah Menengah Atas Negeri 2 Pacitan. Indonesian Journal on Networking and Security, 3(3), 65-70. http://ijns.org/journal/index.php/ijns/ar ticle/view/376

Dewi, I. R., \& Malfiany, R. (2017). Perancangan Sistem Informasi Administrasi Pembayaran Pada Sdit Lampu Iman Karawang Berbasis Visual Basic 6.0. Jurnal Interkom: Jurnal Publikasi Ilmiah Bidang Teknologi Informasi Dan Komunikasi, 12(2), 4-12. https://doi.org/10.35969/interkom.v12i 2.5

Efendi, D. M., Mintoro, S., \& Septiana, I. (2019). Audit Sistem Informasi Pelayanan Perpustakaan Menggunakan Framework Cobit 5.0. Jurnal Informasi Dan Komputer, 7(2), 31-36. https://doi.org/10.35959/jik.v7i2.147

Herlambang, B. A., \& Setyawati, V. A. V. (2015). Perancangan Data Flow Diagram Sistem Pakar Penentuan Kebutuhan Gizi Bagi Individu Normal Berbasis Web. Jurnal Informatika UPGRIS, 1, 78-85. http://103.98.176.9/index.php/JIU/artic le/view/802

Rusmayanti, A. (2015). Sistem Informasi Pengelolaan Keuangan Pada Desa Ngadirejan. Speed - Sentra Penelitian Engineering Dan Edukasi, 6(2), 35-39. http://www.ijns.org/journal/index.php/ speed/article/view/1321/1309

Sriyono, H. (2016). Program Bimbingan Belajar Untuk Membantu Meningkatkan Kemandirian Belajar Siswa. Sosio-E-Kons, 8(2), 118-131.

Syukron, A., \& Hasan, N. (2017). Perancangan Sistem Rawat Jalan Berasis web Pada Puskesmas Winog. Bianglala Informatika, 3(1), 28-34. https://ejournal.bsi.ac.id/ejurnal/index. php/Bianglala/article/view/574/465

Usada, E., Yuniarsyah, Y., \& Rifani, N. (2012). Rancang Bangun Sistem Informasi Jadwal Perkuliahan Berbasis Jquery Mobile Dengan Menggunakan PHP Dan MySQL. JURNAL INFOTEL - Informatika Telekomunikasi Elektronika, $4(2), \quad 40$. https://doi.org/10.20895/infotel.v4i2.1 07

Yusran, Y. (2020). Perancangan Sistem Informasi Administrasi Pembayaran SPP Siswa Berbasis Web. Edik Informatika, $\quad 6(2), \quad 7-14$. https://doi.org/10.22202/ei.2020.v6i2.3 980 